\title{
Mujer campesina y tecnología agroalimentaria en el Perú actual
}

\section{RESUMEN}

El estudio analiza los procesos que se desenvuelven en sectores de pequeńas productoras de alimentos, que inducidas por su relevante contacto con el mercado fluctuante y mundializado, que actualmente revalora los alimentos andinos, están in troduciendo prácticas tecnológicas nuevas en su manejo agrícola, en el procesamiento de productos y en su comercialización. Se busca identificar los factores económicos, culturales e institucionales que condicionan la adopción de innovaciones productivas por parte de la mujer campesina.

Palabras Clave: Mujer campesina y tecnología. Tecnologías agroalimentarias andinas. Género y tecnología agraria en la sierra.

\section{Rural women and food and agricultural technology in Modern Peru}

\begin{abstract}
This study analyzes ongoing processes occurring in certain sectors of local food production, which are influenced by globalized and fluctuating markets that have rediscovered Andean foods. These small food producers are incorporating new technologies into agricultural practices, food production, and product commercialization. This research attempts to identify the economic, cultural and institutional factors that influence the adoption of new technologies by rural women.
\end{abstract}

KEYwORDs: Rural women and technology. Food and agricultural Andean technolgies. Gender and agricultural technologies in the Peruvian Andes. 


\section{Introducción}

E l sector agrícola productor de alimentos del país se ubica en gran medida en la sierra peruana, está conformado generalmente por pequeñas unidades familiares con parcelas menores de cinco hectáreas de extensión, emplean básicamente tecnologías tradicionales e intermedias, que, en general, aplican mano de obra familiar y donde el desempeño productivo agrícola y no agrícola de la mujer en los últimos veinte años viene cobrando cada vez mayor importancia, en el contexto de las transformaciones en las relaciones de trabajo en las economías campesinas.

El censo nacional agropecuario de 2012 registró 1 millón 811 mil pequeñas unidades agropecuarias menores de cinco hectáreas, que representaban cerca del $82 \%$ del total de unidades agropecuarias del país. Las pequeñas unidades agropecuarias se ubican en la región de la sierra, que reúne el $68 \%$ de las mismas. (INEI). Se desenvuelven todavía en economías de subsistencia, afrontan severas limitaciones económicas y tecnológicas y precarias condiciones de vida, una de cuyas manifestaciones es la alta tasa de inseguridad alimentaria, situación contradictoria con la condición de dichos pequeńos productores, que son depositarios de un rico acervo tecnológico ancestral, que domina el cultivo y utilización de diversidad de especies que los mercados del mundo y del país reconocen su importancia, particularmente en la última década. (Repo, R. UNALM).

Las principales tendencias que marcarán grandes cambios en la producción y consumo de alimentos en el mundo durante los próximos años serán: el incremento de la población mundial, los cambios en los hábitos de consumo por el explosivo crecimiento de una nueva clase media con capacidad adquisitiva en los países emergentes, la disminución de las tierras cultivables por el crecimiento urbano y la disminución de la productividad agrícola debido al cambio climático, la degradación de los suelos y la escasez del agua. (Kanashiro, L. ESAN. 2014).

Buscamos indagar y conocer con mayor profundidad los mecanismos y formas cómo la mujer pequeńa productora de alimentos de la sierra sur percibe las nuevas corrientes del mercado, su impacto o respuesta en cuanto a las formas, estrategias y tecnologías que adopta para introducir cambios en el laboreo agrícola, la preparación y procesamiento de los productos agropecuarios y la comercialización de los mismos, así como la importancia que asigna a las cualidades de sus productos tradicionales para la alimentación de su familia. Tratamos de identificar las potencialidades de innovación tecnológico productiva de la mujer agricultora y su familia y a la vez definir sus debilidades, a fin de explorar alternativas institucionales y políticas para el desarrollo humano y sostenible de la pequeña agricultura alimentaria de la sierra.

Las observaciones de campo y encuestas del presente estudio han sido realizadas en áreas rurales de valles interandinos, ocupadas por pequeñas unidades productivas agroalimentarias de manejo familiar, propias del sur andino peruano, ubicadas en las provincias de La Unión, Cotahuasi - Arequipa y de Quispicanchis - Cusco.

\section{Referencias teóricas}

Cerca de la tercera parte de la población del Perú vive en zonas rurales, $50 \%$ de cuyos ingresos económicos provienen de la agricultura. El $25.5 \%$ de la población económicamente activa (PEA) del país trabaja en el sector agropecuario y aporta cerca del $8.4 \%$ del producto bruto interno (PBI) (INEI 2015). Dichas magnitudes nos revelan la importancia que reviste la actividad agropecuaria nacional, la misma que interiormente se caracteriza por una profunda heterogeneidad de tipos de agricultura; su diferenciación se aprecia principalmente por la capacidad económica de las unidades productivas, el área geográfica en que se ubican, el nivel tecnológico que dominan, su acceso al financiamiento y las formas de su articulación al mercado.

El minifundio es el subsector agropecuario que predomina en la producción de alimentos, 1'811,000 unidades agropecuarias menores de $5 \mathrm{Ha}$, que pueden considerarse de pequeños propietarios, representan el $82 \%$ del total de unidades productivas agrarias del país. Geográficamente se distribuyen 15\% en la Costa, 14\% en la Selva y una gran mayoría, de $71 \%$ de las mismas, en la sierra. Dichas unidades productivas, que incluyen a las Comunidades Campesinas y Comunidades Indígenas, generan el $80 \%$ de los productos alimenticios que consume el mercado nacional ${ }^{1}$ Contribuyen para que la población nacional logre una alimentación más autónoma, no sólo en cantidad sino en calidad. A lo cual se agrega la diversidad y el valor nutricional de los

1 Instituto Nacional de Estadística - INEI. IV Censo Nacional Agropecuario. 2012. 
alimentos en la mesa de la familia peruana, considerando que las importaciones y la producción agroindustrial se restringen a pocos renglones.

La región de la sierra peruana reúne a la gran mayoría de las pequeñas unidades agropecuarias, productoras de alimentos para el consumo interno, aunque también es relevante que determinados sectores de las citadas pequeñas unidades agrícolas vienen incursionando en el cultivo de productos alimenticios andinos que destinan a la exportación, entre estos destacan la quinua y la kiwicha, productos que vienen siendo reconocidos en los mercados del mundo por sus cualidades nutritivas y formas de manejo productivo sostenibles, amigables con el entorno ecológico y social. Se ha difundido en los últimos años las bondades gastronómicas, nutritivas y otras cualidades de la agricultura alimentaria andina, como depositaria de un acervo tecnológico de diversidad de cultivos nativos y exóticos destinados a la alimentación humana, sustento en que reposa el boom de la gastronomía peruana.

La agricultura familiar en el Perú guarda la principal reserva genética de la diversidad de cultivos andinos, convirtiéndose en el principal sistema de producción que garantiza la protección de nuestra biodiversidad ecológica y genética, recurso potencial con vista a las necesidades de desarrollo productivo para atender la creciente demanda de alimentos en el mundo.

En muchas regiones y países se ha dado en las últimas décadas un proceso denominado de "feminización de la agricultura", caracterizado por el creciente dominio de las mujeres en la producción agrícola, aparejado por la disminución de la presencia de varones en la actividad. Evolución que es acompañada por el incremento de hogares encabezados por mujeres, debido a la emigración masculina, conflictos armados, abandono y creciente número de madres solteras. Si bien las estadísticas oficiales de América Latina y El Caribe colocan el porcentaje de hogares encabezados por mujeres en un $17 \%$, un estudio realizado por FICA, indica que esa proporción es más alta, así en el caso del Perú alcanza a 43\%. ${ }^{2}$ Para el ańo 2012, las estadísticas del censo agropecuario señalan que un $30 \%$ de unidades agropecuarias del Perú están a cargo de mujeres. ${ }^{3} \mathrm{~A}$ lo anotado cabe agregar que las cifras oficiales infravaloran la proporción de mujeres que poseen y administran explotaciones agrícolas, muchas veces se supone o se da como legalmente reconocido que el varón es el "jefe de

2 Instituto Interamericano de Cooperación Agrícola - FICA. 1994

3 Instituto Nacional de Estadística - INEI. Obra citada. hogar" y responsable de la explotación, aun cuando en los hechos, es la mujer quien se ocupa de las actividades cotidianas y decisiones en el manejo productivo de las pequeńas explotaciones agrícolas.

Es importante profundizar el conocimiento sobre la importancia que actualmente reviste la participación de la mujer en la producción agropecuaria, con énfasis en su acceso a la tecnología, los requerimientos técnicos específicos que demanda, los factores limitantes de su productividad y participación en las decisiones de manejo y organización y, así mismo, evaluar la importancia de su participación en las actividades de post cosecha, procesamiento de productos y comercialización. Las evaluaciones realizadas a los programas de generación y transferencia de tecnología, ejecutados por entidades oficiales y privadas, apuntan que éstos mantienen la concepción estereotipada de patrones de división del trabajo a partir del binomio producción varones y reproducción - mujeres. ${ }^{4} \mathrm{El}$ uso y acceso a la tecnología por parte de los productores de alimentos en nuestro país se hallan similarmente mediatizados por dicha concepción.

Si bien aún persiste la exclusión de la mujer en la oferta tecnológica formal o institucional, se viene dando un proceso informal de adaptación tecnológica que protagonizan las pequeñas agricultoras productoras de alimentos de la sierra, quienes inmersas en las fluctuaciones del mercado globalizado, rescatan los resquicios de eventuales corrientes, como la apreciación registrada de los alimentos andinos en los últimos ańos, para cuyo propósito vienen introduciendo cambios en sus cultivos, adaptando a sus posibilidades y condiciones locales especies y variedades de mayor valor comercial, asimismo, adaptan formas mejoradas de manejo agrícola y de crianza de animales, buscan dar mayor valor de venta a su productos mediante su procesamiento y mejora en su presentación y ensayan nuevas alternativas para su comercialización. Si bien en gran medida, su desenvolvimiento productivo se sustenta todavía en sus conocimientos tradicionales, vienen introduciendo adaptaciones y mejoras a su alcance. Algunos de estos aspectos han sido abordados anteriormente por la autora del presente estudio y en la presente oportunidad se hace un análisis más exhaustivo del tema planteado. ${ }^{5}$

4 Llanos Vargas, Carmen. Mujeres productoras de alimentos en Bolivia. (La Paz. 1996).

5 Loayza A. Sulema. La mujer campesina en la agricultura y seguridad alimentaria. Revista de Sociología. Facultad de Ciencias Sociales. UNMSM. Lima. Julio 2015. 
Las mujeres rurales enfrentan actualmente cambios que tienen que ver con el proceso de globalización de la economía. La respuesta de las pequeńas productoras ante los nuevos contextos que influyen en su quehacer productivo y comercial, es la de adaptar o cambiar su actividad productiva introduciendo transformaciones en la producción agropecuaria, como también están diversificando sus ocupaciones dando relevancia a actividades productivas no agropecuarias, como la transformación y procesamiento de productos y adoptando nuevas alternativas de comercialización. Fenómeno que viene haciéndose extensivo en el sector rural, dando lugar a la denominada pluriactividad de las economías campesinas en la sierra sur.

La expansión del mercado en las zonas rurales ha sido el foco catalizador de los cambios operados, vía la salida de productos y la diversificación de su demanda interna, ofreciendo ciertas oportunidades en un accionar fluctuante e incierto del mercado, que generalmente trae consigo barreras que los pequeños agricultores alimentarios, aún con el empeño redoblado de la mujer campesina, no se hallan en condiciones de responder, dadas sus limitaciones tecnológico culturales y la escasez de sus recursos materiales y de acceso al capital.

Trivelli sugiere que la diversificación hacia actividades productivas no agropecuarias alude estrategias de sobre vivencia frente a la pobre dotación de activos, que caracteriza a la generalidad de pequeńas unidades agropecuarias de la sierra y permite aumentar la productividad del trabajo. La diversificación agropecuaria relacionada con la aplicación de tecnologías intensivas en capital, aumenta la productividad, pero la aplicación de éstas se restringe en particular a las unidades productivas medianas y grandes de la costa. ${ }^{6}$

El sector agroalimentario en el país es el gran motor socioeconómico del mundo rural, es allí donde la mujer juega un rol fundamental, convirtiéndose en pieza clave para el desarrollo económico, social y laboral del medio rural. Las mujeres andinas son quienes articulan el desempeño de las pequeñas unidades productoras de alimentos, sus identidades son fuertemente vertidas en sus capacidades, como actoras centrales en la estrategia económica del hogar y la comunidad. (Rogers 1980).

Las pequeñas productoras agroalimentarias afrontan los problemas generales del agro peruano, entre los que se cuentan los efectos del cambio climático, los elevados

6 Trivelli, C. y Smith, S. Cultivos andinos y el Mercado. El caso del ulluco en la sierra Sur del Perú. CIP. Lima. 1997. costos de insumos y servicios y la pérdida de fertilidad de sus tierras de cultivo. Y más aún, dado que esta problemática no afecta por igual a hombres y mujeres, el apoyo destinado a los productores del campo generalmente soslaya atender las necesidades de las mujeres productoras. Es de suma importancia atender equitativamente las demandas de los pequeńos agricultores, hombres y mujeres, que tengan derechos claros a la tenencia de la tierra y acceso a la capacitación, información y recursos económicos, que les permita adaptarse a las situaciones cambiantes y mejorar la seguridad alimentaria de sus miembros. Se demanda intensificar la capacitación de la mujer en conocimientos tecnológicos y de manejo administrativo, con el fin de propiciar su plena participación en la adopción de decisiones.

El foro "La crisis alimentaria; retos y oportunidades en Los Andes" señala que, la crisis alimentaria y el nuevo contexto internacional traen consigo nuevas necesidades para los países andinos, por lo que es urgente diseñar e implementar nuevas estrategias para su agricultura y desarrollo rural. En todos los casos, urge reconstruir y desarrollar un soporte institucional adecuado para llevar a cabo estos propósitos. (Centro Internacional de la Papa 2009).

La reproducción de la vida en las unidades domésticas, el desarrollo de actividades productivas, la lucha en condiciones adversas en los ámbitos doméstico y productivo, son escenarios comunes en el quehacer que desarrollan las mujeres del campo. Ante las condiciones adversas las mujeres se constituyen como agentes de cambio para afrontar los desafíos a sus pequeñas unidades productivas, diversifican la gama de sus actividades en la producción agroalimentaria, el procesamiento de productos y la comercialización.

La pequeńa agricultura en el Perú se desenvuelve en las áreas rurales, donde la incidencia de la pobreza en la población persiste todavía con caracteres graves. Si bien a nivel nacional y particularmente en los sectores urbanos las campañas sociales iniciadas hace más de diez ańos tuvieron respuesta favorable, habiéndose logrado reducir la pobreza a $25.8 \%$ al ańo 2012 . En el ámbito rural, no obstante, no son perceptibles cambios significativos, registrándose una incidencia de 53.0\% de pobreza el mismo ańo. ${ }^{7}$ Cuadro que se agrava por la persistencia significativa de pobreza extrema (19.7\%) en la población rural del país. La pobreza alcanza caracteres más notorios en torno al desempeño de la mujer

INEI. Nota de Prensa No 067 - 08 de Mayo 2013. 
campesina, por estar sujeta a condiciones socioeconómicas inequitativas, tales como la ausencia de oportunidades y de autonomía económica, escaso acceso a la educación y capacitación tecnológica o profesional, a los servicios de salud, a los recursos económicos y las restricciones condicionadas a su participación en procesos de toma de decisiones.

El Índice de Desarrollo Humano (IDH), que mide la calidad de vida de la persona humana, (PNUD. 2014), muestra los valores de 0.2903 y 0.2919 , para las provincias del área de estudio, La Unión Cotahuasi y Quispicanchis, respectivamente, ubicándolas en el tercio menos desarrollado de las 195 provincias del país. En el caso de La Unión, los factores más negativos que pesan en su escaso desarrollo son el bajo ingreso familiar per cápita de S/. 233.90 por mes y la reducida proporción de pobladores con educación secundaria completa, 32.98\%. Para el caso de Quispicanchis, los factores más negativos son la baja esperanza de vida, 64 años, la escasa formación educativa de su población mayor de 25 años de edad de sólo 5.45 ańos y también el pobre PBI de S/. 318.10 por mes de sus pobladores.

La CEPAL señala que la mujer en la Región representa el $47 \%$ de la fuerza de trabajo total, pero su ingreso per cápita es $50.4 \%$ del ingreso per cápita del hombre. Esta inequidad también se observa en el reducido acceso a los recursos productivos y económicos, como la tierra, agua, crédito, tecnología e insumos agrícolas, no obstante que las mujeres agricultoras participan en todo el proceso productivo. Dicha situación, refiere el mismo organismo, determina la necesidad imperiosa de promover el acceso de las mujeres campesinas a la tecnología, con énfasis en las tecnologías alimentarias, como una estrategia para promover la autonomía, empoderamiento personal y económico de las mujeres, así como incrementar sus ingresos.

La innovación tecnológica, elemento fundamental para incrementar la productividad de los factores productivos agrícolas y de transformación manufacturera, conduce al afianzamiento de la competitividad en el mercado, que alcanza actualmente hasta las comunidades agrícolas más apartadas. Mejorar la productividad en el sector agrario, como en cualquier actividad productiva, demanda la necesidad de desarrollar tecnologías aplicables, en nuestro caso, a las condiciones de las unidades agrícolas familiares de la sierra del Perú. No obstante, la investigación y el desarrollo científico y tecnológico en el Perú, como en algunos países latinoamericanos, afronta serias limitaciones.
El "Informe para el desarrollo humano 2001" adoptado por PNUD hace precisiones relevantes en relación a la importancia de la innovación tecnológica, como un medio por excelencia para alcanzar un desarrollo humano y sostenible. Dicho organismo refiere entre otros temas que "... a lo largo de la historia, la tecnología ha sido un poderoso instrumento de desarrollo humano y reducción de la pobreza y si bien el mercado es un poderoso impulsor del progreso tecnológico, no es tanto que permita crear y difundir las tecnologías". Asi mismo, indica que "la innovación tecnológica eleva la capacidad del hombre en todos los campos de actividad, como son por ejemplo el desarrollo de plantas resistentes a sequias, vacunas para enfermedades contagiosas, fuentes de energía no contaminante, el acceso a la Internet, la información y las comunicaciones", las cuales, adaptadas convenientemente pueden mejorar las salud, la nutrición, los conocimientos y los niveles de vida de las personas y aumentan sus posibilidades de participar más activamente en la vida social, económica y política de la comunidad.

La innovación tecnológica en el Perú, en particular, en el agro de la pequeńa agricultura productora de alimentos de la sierra, sufre de serias limitaciones.. Existen, no obstante. algunos esfuerzos puntuales y aislados que deberían rescatarse y potenciarse para diseminar sus experiencias, buscando las adaptaciones que la diversidad de situaciones y condiciones que el medio geográfico y la situación socio económica de cada zona lo exigen. Elías, I. refiere haber identificado en la sierra sur 18 tecnologías muy sencillas y de bajo costo, que pudieron incrementar la productividad y el ingreso de minifundistas, que antes se encontraban en situación de pobreza y de extrema pobreza. ${ }^{8}$

La realidad agraria nacional es muy diversa. Existen segmentos con necesidades y carencias en innovación y desarrollo muy distintas, así como diferencias grandes en capacidades y recursos. No obstante, el agro ha sido y sigue siendo fundamental para el crecimiento económico del país. El Ministerio de Agricultura ha adoptado últimamente una caracterización de la diversidad de situaciones del sector agropecuario en cuatro segmentos, los primeros dos segmentos corresponden a los de mayor desarrollo y capacidad económica, asentados casi en su totalidad en la costa, un tercer segmento agrupa a todos los cultivos con potencial exportable y que requieren un mayor apoyo para generar tecnología y así alcanzar niveles de inversión para su desarrollo;

$8 \quad$ Elías, Inés. Cuadernos de Investigación. UPC. Lima. 2010. 
entre estos últimos considera los cultivos y crianzas que se vienen promocionando desde el sector privado que incluyen los cultivos de quinua y kiwicha, como el programa que la ONG AEDES viene promocionando en la provincia de La Unión - Arequipa y las mejoras en cultivos de hortalizas y de crianza tecnificada de cuyes, que se ha promocionado en la provincia de Quispicanchis - Cusco. $\mathrm{Al}$ respecto cabe mencionar, sin embargo, que las estrategias adoptadas para promocionar dicho tercer segmento agrícola vienen tropezando con serias dificultades derivadas de la propia naturaleza de los mercados, relativas a las fluctuaciones de la demanda y la competencia surgida en diversas latitudes del mundo.

El cuarto segmento que el Ministerio de Agricultura distingue, es el de los cultivos llamados de subsistencia, conducidos por unas 400 mil familias de pequeños productores minifundistas asentados en pequeños valles y laderas de la sierra. Este segmento, predominante en número, ocupa micro parcelas de tierra de una agricultura extensiva, de baja rentabilidad y poco competitiva, conducida por agricultores de bajo nivel educativo, generalmente mujeres y que adolecen de limitado acceso a servicios básicos y productivos.

Los avances que ha logrado la denominada Revolución Verde en lo referente a incrementar los rendimientos y la productividad agrícola, han sido importantes, al haber desarrollado por ejemplo semillas de variedades mejoradas, por medio de la biotecnología y plantas transgénicas, que actualmente se aplican en explotaciones intensivas en capital en diversos países, sin embargo, en el caso del Perú y particularmente en la sierra, su implantación trae consigo el riesgo que puede atentar contra la biodiversidad natural. En este sentido, debe destacarse el papel que han jugado las pequeñas mujeres agricultoras en la conservación de la diversidad genética en sus cultivos. No obstante, son pocos los estudios sobre el rol de la sociedad y menos aún de la mujer en los cambios de la evolución de las especies y la biodiversidad. (FAO. 2005). Estudios como los de Poats y Cuvi (2007), ponen énfasis en la importante contribución que cumplen las mujeres en la reproducción de variedades de semillas y granos nativos. Referimos, así mismo, nuestros anteriores estudios (Loayza, S. 2015), que la mujer campesina del sur andino, cumple un papel relevante en el trabajo productivo de las pequeñas unidades familiares, viene acrecentando sus vínculos con las prácticas de post cosecha, el procesamiento de productos y la comercialización, manteniendo siempre su cercanía, en forma asociada, con el laboreo agropecuario. Sin em- bargo, los paquetes tecnológicos que se generan y se le ofrecen soslayan la diversidad de dichos componentes de su actividad, dejándola desprotegida del respaldo de una mayor eficiencia y especialización productiva.

La eficiencia de la explotación agrícola aparece como el objetivo central en los estudios relativos a la innovación tecnológica y productividad. Así, Escobal, J. (2006), en su estudio sobre la eficiencia y sus determinantes en la pequeña agricultura comercial, señala que el principal determinante de los niveles de eficiencia alcanzados, es, sin lugar a dudas, el nivel de educación y conocimientos técnicos del productor, anota también que existen otros factores determinantes de importancia, como son la escala de producción, el acceso al crédito y la disponibilidad de recursos.

Objetivamente se reconoce que actualmente ya es muy difícil referirse a una tecnología agropecuaria tradicional o a un patrón tradicional de cultivos, por cuanto que los pequeños agricultores, particularmente durante los últimos quinquenios, han recibido y adoptado técnicas mejoradas, que responden a su posicionamiento en el mercado, tenencia de tierras, nivel educativo, tamaño de familia, participación en organizaciones productivas y sociales, así como a las campañas de capacitación y extensión agraria. La gran diversidad de las características agroecológicas del país, hace que las tecnologías recomendadas sean también diferentes entre regiones, ámbitos geográficos y sistemas de producción existentes.

La importancia de la participación de las mujeres en la economía campesina no radica exclusivamente en la intensidad y diversidad de sus labores productivas y reproductivas, sino en el significado que tienen sus muy diversas funciones, de administración y organización en la transformación productiva que les exige el entorno. Las mujeres campesinas son responsables de la estrategia de sobrevivencia familiar y de articular momentos y espacios del proceso productivo de la unidad campesina. De las experiencias de proyectos y programas de promoción agropecuaria, es posible concluir que la capacidad productiva de las mujeres campesina, fortalecida con una capacitación técnica - organizativa, y acceso a recursos tecnológicos y productivos, contribuye al desarrollo del sector campesino.

La tecnología es la clave que nos permite explicar el desarrollo de las fuerzas productivas. El nivel de desarrollo tecnológico y las formas que adopta explican cómo se combinan los factores de la producción (tierra, capital y trabajo) y las alternativas de su desarrollo. Las 
economías campesinas no funcionan necesariamente bajo los parámetros del sistema capitalista, de las leyes del mercado, los salarios, ni rentabilidad máxima, reúnen mas bien un acervo tecnológico y cultural diverso, que estructuran formas de producción y consumo amigables con el entorno natural y la biodiversidad, económica y socialmente sostenibles. Se pretende así que la transferencia de tecnología esté de acuerdo con las condiciones del ecosistema, la cultura, formas de organización y cooperación en el trabajo y la cosmovisión de los pequeños agricultores.

\section{Prácticas tecnológico productivas de la mujer campesina}

La agricultura en los Andes del Perú enfrenta un medio ecológico altamente variado, que involucra afrontar severos riesgos, en donde las alternativas de sostenibilidad de las pequeñas unidades productivas se basan en el uso adecuado de la biodiversidad, los pisos ecológicos, calidad y relieve de los suelos, entre otros. Las culturas ancestrales han sabido desarrollar sus prácticas agropecuarias, formas de conservación y procesamiento de productos, han adaptado formas de manejo del terreno, semillas de variedades de especies y han dado valor de uso a diversidad especies nativas. De esta forma la agricultura andina se ha constituido a lo largo de la historia en una de las grandes aportantes de recursos alimenticios, que actualmente cobran creciente importancia a nivel mundial.

Las características de la población campesina andina y el entorno socioeconómico de sus sistemas agrícolas permiten explicar el papel desempeńado por la mujer agricultora y su relación con la conservación, evolución y uso de los recursos fitogenéticos andinos. Entre los cultivos que la mujer campesina ha participado en domesticar y que actualmente maneja en los Andes, destacan por su importancia para la seguridad alimentaria, el maíz y las papas en sus diversas variedades. ${ }^{9}$ Sin embargo y para adecuar el nivel nutricional de la dieta familiar, la mujer campesina mantiene en producción agrícola otras especies que le permiten diversificar la alimentación y dar un uso más racional y sostenible a sus tierras.

Además de los papeles decisivos en la producción de alimentos, las mujeres campesinas contribuyen a

$9 \quad$ De La Torre, Ana. 1988. la seguridad alimentaria de otros modos importantes, como aquellos que preservan la biodiversidad de los recursos fito genéticos, ampliamente reconocidos como esenciales para la seguridad alimentaria. Al ser las responsables de la producción de alimentos y del cuidado de la familia, las mujeres del campo conservan los conocimientos ancestrales sobre el valor y diversidad de usos de plantas aptas para la nutrición y la salud, suelen experimentar y adaptar especies nativas y a menudo son las guardianas de sus diferentes aplicaciones.

Las familias de las mujeres agricultoras entrevistadas en ambas provincias corresponden en $80 \%$ de casos a parejas casadas $(75 \%)$ y convivientes $(5 \%)$, en todos los casos con hijos. El número promedio de hijos en las dos provincias es de 4.7 por hogar, siendo algo menor en La Unión, que conlleva a afirmar que en Quispicanchis dispondrían de una relativa mayor presencia de fuerza de trabajo familiar.

La ocupación principal de las entrevistadas en las dos provincias es la agricultura, así $95 \%$ de las mujeres en La Unión son agricultoras y si bien sólo $48 \%$ de mujeres de Quispicanchis refieren ser agricultoras, otro $38 \%$ son amas de casa, que se desempeñan también en la agricultura para el sustento de la unidad familiar. En general, es perceptible que la mujer agricultora sur andina incursiona crecientemente en la pluriactividad ocupacional. Un 65\% de cónyuges de las entrevistadas en ambas provincias tienen por ocupación principal la agricultura.

Los servicios básicos y otras facilidades que las entrevistadas refieren disponer en el hogar, comprenden 95\% de hogares con suministro agua de red en su vivienda y la totalidad de viviendas en ambas provincias tienen suministro de servicio eléctrico. El uso de leńa como combustible para la cocción de los alimentos es todavía predominante en ambas provincias. El 98\% de mujeres entrevistadas en las dos provincias disponen de equipos de radio, $58 \%$ tienen televisión y $95 \%$ cuentan con teléfonos celulares. No se registró entrevistada alguna que dispusiera de Internet.

\section{Manejo aj175gricola}

La tenencia de tierras en propiedad de las agricultoras entrevistadas en las dos provincias es de 4 parcelas en promedio, con una extensión de 4.5 topos por cada predio, siendo mayores en La Unión, donde el número promedio de parcelas es de 5 y el tamaño promedio por predio de 6.5 topos, mientras que en Quispicanchis 
el número promedio de parcelas es 3 , con una extensión total promedio de 2.3 topos por cada predio. La totalidad de parcelas en La Unión disponen de agua de riego, en Quispicanchis un sector minoritario de agricultoras tienen parcelas de secano, en promedio de 0.5 topos de tamaño. (Un topo equivale a 0.33 Has.) En la provincia de Quispicanchis un sector minoritario de entrevistadas, disponen adicionalmente cada una de una parcela con agua de riego, de 0.6 topos de tamaño promedio.

Los principales cultivos de la última campaña agrícola, referidos por las entrevistadas, son la quinua y kiwicha, que en los últimos años han cobrado mayor importancia en La Unión, a los que en dicha provincia destinan en promedio 2.2 topos y 3.1 topos y obtienen $1,540 \mathrm{Kg} /$ año y 3,229 Kg/año, respectivamente, mientras que en Quispicanchis sólo se reportó el cultivo de quinua en un promedio de 0.2 topos y una producción de $67 \mathrm{Kg} / a n ̃ o$, les sigue en importancia el cultivo de papas, al que destinan en promedio 0.9 topos en $\mathrm{La}$ Unión, con una producción promedio de 3,900 Kg/ año y en Quispicanchis 0.4 topos, con una producción de 1,100 Kg/año; el cultivo de maíz comprende en promedio 1.0 topos en La Unión y producen 480 $\mathrm{Kg}$ /año del grano y en Quispicanchis cultivan en promedio 0.6 topos de los que obtienen $280 \mathrm{Kg} /$ ańo; los cultivos de cebada comprenden en promedio 0.9 topos en la Unión, con una producción de $330 \mathrm{Kg} /$ año y en Quispicanchis 0.5 topos, que producen $200 \mathrm{Kg} /$ año. les sigue en importancia el cultivo de tarwi, al que destinan en promedio 0.7 topos en La Unión, obteniendo $250 \mathrm{Kg} / \mathrm{año}$ de esta leguminosa y 0,3 topos en Quispicanchis, obteniendo una producción de $190 \mathrm{~kg} /$ año.

Los agricultores de La Unión cultivan alfalfa para la alimentación de su ganado, destinan a este forraje en promedio 1.6 topos de tierras, del que obtienen 20 TM en cinco cortes anuales, en Quispicanchis, el ganado es criado mayormente por pastoreo extensivo y destinan en promedio sólo 0.1 topos para cultivar alfalfa, obteniendo 1.4 TM en cuatro cortes anuales.

Otros cultivos de menor significancia en las citadas provincias son el trigo, arveja, hortalizas y flores. Estos dos últimos sólo fueron referidos por las campesinas de Quispicanchis, quienes les asignan importancia, porque dominan las formas y cadenas de comercialización de hortalizas y flores, inclusive fuera de su región. Otros cultivos de menor significancia son el trigo y la arveja.

El 89.5\% de las mujeres entrevistadas en La Unión y $100.0 \%$ en Quispicanchis tienen huerta, cuyo tama- ño promedio en La unión es de $510.7 \mathrm{~m}^{2}$ y en Quispicanchis es sólo de $133.0 \mathrm{~m}^{2}$. Entre los cultivos de las huertas se distingue que en La unión el $47.1 \%$ tienen hortalizas y $29.4 \%$ frutales, en Quispicanchis el $40.0 \%$ cultiva hortalizas y $24.3 \%$ hortalizas y flores.

La preparación del terreno por arado o barbecho, que consiste en remover el terreno a cierta profundidad, es realizado generalmente con arado de bueyes (yunta) y también con tractor (normalmente alquilado), aunque también utilizan herramientas manuales, como pico, pala y chaquitaclla. El hombre generalmente realiza el arado y la mujer, con ayuda de los hijos o sin ellos, hace el desterronado utilizando pico o lampa, como también limpia las piedras y rastrojos del terreno, trasladándolos fuera del área de cultivo.

El $100.0 \%$ de las mujeres agricultoras entrevistadas, tanto de la provincia de La Unión como de Quispicanchis sostienen que el trabajo de preparación que realizan en sus terrenos con riego es el barbecho más el deshierbo. En $52 \%$ de casos en La Unión y $42 \%$ de Quispicanchis, riega el terreno antes del barbecho, que se realiza con arado de yuntas de bueyes, otro sector de 52\% de casos de La Unión y 15\% de casos de Quispicanchis lo realizan por tractoreo. En esta última provincia un $45 \%$ de casos combinan el arado con yuntas de bueyes con el uso de chaquitacllas, cuando los terrenos son en declive.

El 94.7\% riega sus chacras por inundación tradicional y el 5.3\% riega por rociado o aspersión. El 100.0\% en la provincia de La Unión lo hace por inundación y $10.5 \%$ en Quispicanchis lo hace por aspersión. En La Unión el 53.3\% de entrevistadas considera que el agua de riego que disponen es suficiente y el $46.7 \%$ afirma que no es suficiente; y en Quispicanchis, el 60.0\% considera que es suficiente y $40.0 \%$ considera lo contrario.

Los pequeños agricultores asignan extremada importancia a la necesidad de asegurar el suministro de agua a sus cultivos, lo que explica que $91.2 \%$ de ellos pertenece a una organización de regantes. La tendencia se repite en las dos provincias. El pequeño margen de estos productores agrarios no integrados a una organización de regantes, es por que sus predios se hallan junto a cursos de agua de acceso directo. La asignación de la cuota de riego agrícola corresponde en $30.8 \%$ de mujeres entrevistas de La Unión que reciben una vez cada semana y el $61.5 \%$ de las mismas señala que reciben cada 10 días; en Quispicanchis, el 18.2\% señala que la cuota es interdiaria, el 63.6\% señala que es semanal y el 18.2\% que la cuota es cada vez que la solicitan. 
El riego de los cultivos, casi en su totalidad es por inundación y lo hacen las parejas de agricultores en forma compartida, corre a cargo del varón la captación del agua de compuertas y su conducción por canales o sequias hacia el predio, la mujer se encarga de distribuir el agua en cada parcela, en cuya realización su experiencia le permite concluir el riego dentro de la cuota de tiempo asignado por la autoridad competente. Los sistemas de riego por gravedad e inundación generan pérdidas de agua por infiltración y evaporación y demandan la atención permanente del regante. Dichas limitaciones no reciben la atención necesaria de las instituciones y entidades vinculadas al agro, no obstante que hay experiencias aisladas de técnicas de riego mejoradas y económicas adaptadas en zonas alto andinas y valles de la sierra.

La siembra se realiza generalmente por surqueo, también con yunta de bueyes o con tractor. La mujer es quien hecha manualmente la semilla en la tierra, avanzando detrás de la yunta, conforme a una práctica ancestral que la relaciona con la fertilidad del suelo. La siembra generalmente convoca también la participación de los hijos, particularmente, cuando en la misma oportunidad se agrega fertilizantes al terreno.

El aporque de los cultivos es realizado generalmente por las parejas de agricultores, utilizando para ello lampas manuales, aunque también hay sectores minoritarios de mujeres que realizan solas dicha labor. Dicha labor cultural exige ser realizada en oportunidades definidas según el estado del cultivo, habiéndose percibido por referencias de las propias entrevistadas que muchas veces posponen realizar el aporque, porque no tienen tiempo, lo cual afecta el desarrollo de las plantas y el rendimiento de los cultivos.

El uso de equipos mecanizados es asumido normalmente por los varones, entre estos elementos se cuentan los tractores (aunque son normalmente alquilados, incluido el pago por tractoreo) y rociadores de compresora para fumigación, generalmente son los varones quienes operan los aparejos, tal como el arado de bueyes, que demanda mayor esfuerzo físico,. Esta limitación del acceso de las mujeres al uso de equipos mecanizados se estima que puede ser superada, tanto por su entrenamiento y capacitación, como por el diseño y adaptación de tales elementos a las condiciones físicas de la mujer, avance que en algunos países desarrollados ya se viene dando. El potencial productivo agropecuario de la mujer tanto en el país como en el resto del mundo, amerita el desarrollo tecnológico de tales equipamientos, lo que permitiría incrementar sustancialmente los rendimientos productivos del agro.

En general, no existe suficiente conciencia social sobre la contribución de las mujeres de las pequeñas unidades agrícolas productoras de alimentos, dando lugar a que no sea cabalmente reconocida ni valorada en su importancia económica, social, cultural y ambiental. Siguen siendo deficientes las posibilidades al alcance de la mujer para acceder al capital (crédito), insumos y capacitación tecnológica, que se ajusten a sus necesidades y permitan el crecimiento sostenible de su productividad.

El trabajo de la mujer en la agricultura alimentaria preserva los conocimientos ancestrales pero también introduce innovaciones y desarrolla formas de trabajo y habilidades. Existe un enorme cúmulo de conocimientos propios de los pequeños agricultores, en particular de la mujer campesina, que se expresa, por ejemplo, en el manejo diversificado y altamente flexible de la chacra, dichos conocimientos son todavía poco entendidos, reconocidos y difundidos por la ciencia y tecnología formales. No sólo son agricultoras, sino también adaptadoras de tecnologías, creadoras y conservadoras de la extraordinaria agro diversidad andina, que sustenta actualmente el desarrollo de su gastronomía, una de las más apreciadas del mundo.

Entre los diversos problemas que afronta la agricultura de la sierra, asociado a la limitada extensión de tierras de cultivo, es el accidentado relieve del terreno, lo cual ocasiona que las tierras de pendientes se erosionen por el laboreo, sobre todo por arado, siembra y riego. Los antiguos peruanos afrontaron seriamente estos problemas y construyeron grandes extensiones de terraplenes o andenes en las faldas de los cerros, técnica que les posibilitó ampliar las extensiones cultivadas y aplicarles riego, controlar la erosión, más otros beneficios ambientales y productivos. Actualmente es perceptible la existencia de importantes extensiones de tierras de andenerías, sobre todo en la provincia de La Unión y, en menor medida, en Quispicanchis, las mismas que sólo en menores extensiones se hallan cultivadas. No existen acciones institucionales orientadas al rescate y puesta en valor de dicha infraestructura productiva en ninguna de las dos provincias, y se desconoce la existencia de investigaciones científicas y tecnológicas conducentes a la adaptación de sistemas, equipos y otros recursos tecnológicos modernos para innovar las tecnologías ancestrales a las exigencias de productividad y competitividad actuales. 
Las semillas que los pequeños agricultores utilizan, son generalmente obtenidas por las mujeres, que seleccionan de sus cosechas y también intercambian semillas con campesinos vecinos. La alternativa de emplear semillas mejoradas, muchas veces no es viable para estos campesinos, por los mayores desembolsos que les implica adquirir tales semillas, más el requisito de agregar fertilizantes y plaguicidas, que multiplican los costos.

Las familias campesinas que usan tractor en el laboreo de sus tierras generalmente lo hacen alquilando los equipos, en Quispicanchis el $100.0 \%$ alquilan y en La Unión el $11.1 \%$ dispone de tractor propio, $11.1 \%$ dispone de tractor prestado y $77.8 \%$ alquilan. Respecto a la disposición de la yuntas de bueyes, aproximadamente en ambas provincias el 43\% dispone de yunta propia, $17 \%$ dispone de yunta en alquiler y $40 \%$ dispone de yunta en préstamo.

Otra labor que realiza la mujer en las dos provincias es la de acumular y conservar el guano de corral y su aplicación como fertilizante, reciclando en forma sostenible dicha materia orgánica propia, que constituye el principal fertilizante de sus cultivos. En La Unión $63.6 \%$ de familias emplean el guano de corral, otro $27.3 \%$ lo combinan con guano de isla y $9.1 \%$ emplean solo guano de isla. En Quispicanchis, 76.2\% emplean guano de corral, $19.0 \%$ lo combinan con compost y otro $4.8 \%$ lo combinan con fertilizante sintético.

En la provincia La Unión las principales plagas o enfermedades del cultivo de la papa son la gusanera, la rancha, papa curo, seca seca y pulgón verde. A la quinua y la kiwicha las ataca principalmente la rancha, al maíz lo atacan el silhui y la gusanera y a las hortalizas la rancha. En Quispicanchis las principales plagas del cultivo de la papa son la rancha, el huaytu y la sarna común, las principales enfermedades del cultivo del maíz son la gusanera y la polilla.

En ambas provincias una gran mayoría de pequeños agricultores combaten las plagas y enfermedades de los cultivos de papas y de maíz utilizando agroquímicos como el Biol y otros insecticidas; en La Unión sólo aplican el lavado en los cultivos de quinua y kiwicha. En todos los casos, la utilización de rociadores con mochilas entre dichos agricultores es generalizada, inclusive para los simples lavados con agua. En Quispicanchis intercalan hojas de eucalipto en el maíz cosechado y seco que almacenan, como repelente de los insectos.

La participación productiva de la mujer se manifiesta igualmente con caracteres relevantes bajo la óp- tica del tipo de cultivos, con un comportamiento bastante similar en las dos provincias en el caso del cultivo de hortalizas, verduras y flores lo realizan 96\% de las entrevistadas, los cultivos de menestras, como habas y arvejas los realizan $80 \%$ de entrevistas, cobra un peso mayoritario de $61 \%$ la participación de las entrevistadas en el cultivo de papas y ollucos y una mayoría relativa de dichas mujeres realizan los cultivos de granos, como maíz, trigo y quinua, el trabajo compartido de las parejas le sigue en importancia, según la frecuencia referida por las mujeres. El cultivo de alfalfa lo realizan las parejas, generalmente en forma compartida

La tecnología que los pequeños campesinos están en condiciones de practicar en la producción agroalimentaria corresponde a una agricultura tradicional, que se desenvuelve al mínimo costo, generalmente sin aplicación de recursos ni de insumos tecnológicos modernos. Los pocos instrumentos mecanizados que usan son alquilados (tractores), sólo en el caso del cultivo de hortalizas usan agroquímicos, lo que se explica porque este cultivo se destina al mercado. La semilla que utilizan la obtienen por selección de su propia cosecha anterior o bien del intercambio con productores vecinos. La limpieza de los cultivos se lleva a cabo en forma manual, escasamente algunos agricultores aplican productos químicos tales como fertilizantes, herbicidas y otros para el control de insectos.

Las economías campesinas compiten desigualmente por carecer de recursos financieros, de infraestructura productiva, comercial, social y física, como es posible apreciar de los análisis expuestos, a lo cual contribuye la inviabilidad generalizada de los paquetes tecnológicos ofertados y la privatización de entidades del estado y otros organismos, que en el pasado, atendían algunos requerimientos de los pequeños productores.

La brecha tecnológica en el país ha crecido, por un lado, la agroindustria y la agricultura comercial, que disponen de recursos económicos, financieros y tecnológicos y entran a competir en los mercados de exportación, y por otro lado, las economías campesinas, que en su gran mayoría presentan fuertes restricciones de capital, escasas posibilidades de acceder al crédito y limitaciones tecnológico productivas, que impiden o limitan las posibilidades de su desarrollo. El estudio del problema tecnológico encierra el problema estructural de la barrera presupuestaria de las economías campesinas para acceder a los paquetes tecnológicos. Estos resultan poco viables para el pequeńo productor que debe recurrir al ingenio y a la creatividad para mejorar 
su producción y evitar quedar fuera del mercado por la competencia que hoy por hoy resulta ser más intensa por las políticas de liberalización económica.

En las comunidades campesinas la aversión al riesgo es generalizada entre los agricultores hombres y mujeres, más aún frente a cualquier novedad tecnológica. Mientras no se vea en la chacra vecina, no hacen uso extensivo de la misma. Luego que se convencen que la tecnología les brinda beneficios no dudan en adaptarla, siendo ésta la forma preferida por los campesinos para adoptar alguna innovación, mecanismo que debería considerarse en su aspecto positivo para orientar las campañas de promoción externas. Se ha constatado que las mujeres productoras adoptan criterios que les permite orientar la generación, validación y adopción de alternativas tecnológicas, tales como el impacto de su costo sobre el ingreso familiar y las condiciones de vida, el efecto sobre la demanda, el impacto sobre la división del trabajo familiar y la orientación del producto, sea al mercado, a su transformación o procesamiento, o bien al autoconsumo, particularmente en los casos de introducción de nuevas variedades así como en la utilización de insumos.

Los pequeños productores agropecuarios son muy vulnerables a la ocurrencia de eventos inesperados, sean estos riesgos inherentes a la agricultura, al clima u otros fenómenos naturales, por ello adoptan estrategias para limitar su exposición a los riesgos. Estas estrategias pueden perjudicar su eficiencia, al llevarlos a no implementar proyectos o tecnologías nuevas o inversiones de alta rentabilidad, y optan por alternativas menos riesgosas pero también menos rentables.

La persistencia de una racionalidad económica expresada en el acervo de conocimientos técnicos y arreglos productivos que han sido desarrollados en un largo proceso de experimentación, que en el caso andino tiene miles de años, mantiene una coherencia interna en la utilización y adecuación de recursos, que junto a una especial adaptación al ecosistema, han permitido el desenvolvimiento de estas sociedades que respetan los equilibrios entre naturaleza y sociedad. Las sociedades campesinas han sabido adecuar sus sistemas productivos, sus formas sociales y la relación con la sociedad global en un proceso permanente de transformación y de adaptación, con el objeto de ser capaces de recrear sus más elementales medios de subsistencia y reproducción.

Respecto a lo que podríamos llamar experiencias constructivas se vislumbran diferentes estrategias que las propias mujeres adoptan para llevar adelante el desarrollo de sus territorios y mejorar el nivel de vida de sus familias. Estas abarcan una diversidad de formas de control, uso de sus recursos, desde aquellos relacionados a la protección de la seguridad alimentaria como el caso del rescate y utilización de los conocimientos ancestrales relacionados con el uso de semillas, que buscan dinamizar y poner en valor activos culturales, naturales y sociales ligados a sus territorios, sea mediante el aprovechamiento de cultivos autóctonos, el manejo sustentable de los recursos naturales y el aseguramiento de recursos básicos. La inversión agrícola es riesgosa, depende de las condiciones climáticas en momentos específicos del ciclo productivo, por otro lado los precios agrícolas son variables, a los cuales son más vulnerables los pequeños productores. Lo que explica que dichos pequeños productores optan por inversiones más seguras y menos rentables antes que por proyectos más rentables, que pueden ser más riesgosos.

\section{Crianza de ganado y animales menores}

La crianza de ganado por parte de los pequeños agricultores en ambas provincias complementa su producción agrícola de pequeńa escala, siendo relevante la crianza de bovinos, que en La Unión alcanza a un promedio de 6.2 cabezas por familia y en Quispicanchis de $3.2 \mathrm{ca}-$ bezas, cuyas ventas promedio por año son de 3.8 cabezas y 1.4 cabezas, respectivamente y cuyos beneficios, adicionalmente a su valor como recurso alimentario es que los toros constituyen su capital de trabajo para el arado de las tierras y las vacas producen leche, para la alimentación. La crianza de porcinos por las mismas familias alcanza a un promedio de 3.6 cabezas en La Unión y a 2.2 cabezas en Quispicanchis, de los cuales benefician o venden anualmente un promedio de 3.2 cabezas en La Unión y 1.1 cabezas en Quispicanchis.

Cobra también importancia la crianza de ovinos, de los cuales tienen en promedio 6.6 cabezas en La Unión y 10 cabezas en Quispicanchis, con una venta promedio anual de 2.8 cabezas y 1.7 cabezas, respectivamente. Similarmente, resalta la importancia de la cría de cuyes por dichas familias, con un promedio de 28.2 cabezas en La Unión y 48.2 cabezas en Quispicanchis, de los cuales venden en promedio 15.3 cabezas y 20 cabezas, respectivamente. Estas dos especies, sobre todo los cuyes, los venden beneficiados y también autoconsumen, favoreciendo así a la seguridad alimentaria familiar. 
Otras crianzas referidas por las entrevistas son las de equinos (caballos y burros), siendo más importante en La Unión, donde alcanza un promedio de 4.4 cabezas por familia, mientras que en Quispicanchis tienen burros, en promedio de una cabeza por familia. Estos semovientes los destinan al transporte de personas y de carga, generalmente no los venden. También se ha referido la crianza de gallinas, en promedio de $16.2 \mathrm{ca}-$ bezas por familia en ambas provincias, más la de patos en promedio de 15 cabezas por familia en La Unión y 4.0 cabezas en Quispicanchis.

Todas estas crianzas contribuyen a generar ingresos y refuerzan la seguridad alimentaria de las familias, bajo el manejo y estrategias productivas y reproductivas conducidas por la mujer campesina. Contribuyen igualmente al sostenimiento de una producción agroalimentaria ambiental y económicamente sostenible. La participación productiva familiar en la crianza de ganado y animales menores se manifiesta con caracteres similares en las dos provincias, si bien hay una relativa mayor participación de los cónyuges varones en la crianza de vacunos, dicha labor es compartida en un promedio de $39 \%$ de casos por las parejas de agricultores y en $36 \%$ de casos en la crianza de equinos. La crianza de porcinos, así como de aves de corral y cuyes son actividades realizadas en más de $90 \%$ de casos por las mujeres entrevistadas, que adicionalmente las complementan realizando ellas mismas el procesamiento y comercialización de productos.

Según las pequeñas productoras entrevistadas en las dos provincias, un $55 \%$ de casos refieren que su ganado vacuno en parte es de raza mejorada, un $25 \%$ refiere que todo su ganado vacuno es de raza mejorada y un $20 \%$, que no tienen vacunos mejorados. En cuanto al ganado equino son perceptibles notables diferencias, en La Unión un 70\% de casos refieren que sus caballos y burros son en parte de raza mejorada, el resto no lo es y en Quispicanchis todos sus equinos no son de raza mejorada. El ganado porcino en $71 \%$ de casos en Quispicanchis es de raza mejorada, el resto no lo es y en La Unión en 63\% de casos son en parte de raza mejorada, el resto no es mejorado. Las gallináceas en La Unión son mejoradas en 11\% de casos, $63 \%$ de casos son mejorados en parte y $26 \%$ de casos no son mejorados, en Quispicanchis sólo en 45\% de casos son mejorados en parte y el resto no lo son. Los cuyes en $29 \%$ de casos de La Unión son de raza mejorada y solo 14\% de casos lo son en Quispicanchis, en La Unión en $35 \%$ de casos los cuyes son en parte de raza mejorada y otro 35\% no lo son y en Quispicanchis 48\% de casos son en parte de raza mejorada y en $38 \%$ de crianzas no tienen ninguna mejora.

Según las mismas entrevistadas, en La Unión las enfermedades del ganado vacuno son la mastitis en $60 \%$ de casos, triquinosis en $20 \%$ de casos y jallu jallu, en otro $20 \% \%$ de casos; los ovinos son atacados por garrapatas en $75 \% \%$ de casos y parásitos en $25 \%$ de casos, a los chanchos las enfermedades que más afec$\tan$ son las garrapatas en $83.3 \%$ y parásitos en $16.7 \%$ de casos; a las gallináceas les afecta el moquillo según $100.0 \%$ de entrevistadas; los cuyes padecen del pique según $100.0 \%$ de entrevistadas. En Quispicanchis las enfermedades que más afectan al ganado porcino son las garrapatas, según $100 \%$ de entrevistadas; las gallinas y otras aves padecen de moquillo en $75 \%$ y de diarrea en $25 \%$ de casos, los cuyes tienen pulga en $67 \%$ y la hitta en $33.3 \%$ de casos entrevistados.

\section{Procesamiento y comercialización de productos}

Las economías campesinas presentan una fuerte integración al mercado en condiciones de subordinación al gran capital, a los requerimientos urbanos, a la presión agroexportadora y a las medidas de ajuste macroeconómico. La mujer campesina se constituye en la agente de las pequeñas unidades agrícolas productoras de alimentos del sur andino, por ser la protagonista del pequeño negocio comercial de las unidades familiares productoras de alimentos, la mujer compulsa los vaivenes del mercado y busca adecuar su actividad agrícola y de procesamiento de alimentos, dentro de las limitaciones que afronta, sorteando los riesgos de situaciones que atentan contra su frágil economía. ${ }^{10}$ Ello explica también que es la mujer campesina quien adopta actualmente estrategias de diversificación productiva no agrícola en el medio rural sur-andino, emprendiendo actividades de procesamiento, transformación y comercialización de sus productos agroalimentarios con valor agregado.

Los procesos de transformación y comercialización de alimentos, realizados fundamentalmente por la mujer, se inician en la cosecha de productos, con participación de toda la familia, siendo la mujer quien adopta las decisiones, tales como la selección de variedades y condiciones adecuadas para los diversos usos y formas de procesamiento, las cantidades a producir, la organización familiar en tales labores, así como el

10 Loayza, Sulema. Obra citada 
planeamiento en el tiempo de las épocas adecuadas y el destino comercial o de autoconsumo de los productos transformados.

La transformación básica de los productos alimenticios en las unidades campesinas se encuentra ligada y confundida con el rol reproductivo de la mujer. La variada tecnología tradicional utilizada para el procesamiento alimentario es artesanal, basada en prácticas heredadas por las mujeres, responsables de la alimentación familiar. Es perceptible, sin embargo, la aparición en la provincia de La Unión, de contadas microindustrias procesadoras y embazadoras de granos, generalmente conducidas por mujeres y que operan como ofertantes de servicios. En Quispicanchis se han dado esfuerzos puntuales de creación de microempresas asociativas de crianza, beneficio, transformación y comercialización de cuyes, manejadas por mujeres, que en la actualidad se encuentran en consolidación.

Los problemas que enfrentan las productoras campesinas para vender sus productos son, entre otros, la incertidumbre en torno al precio y su alta vulnerabilidad en el tiempo, que tiene que ver con factores tanto internos como externos, sus limitaciones de información comercial oportuna, la escasez de transporte adecuado, los límites de perecibilidad de los productos, entre otros. En el caso de los pequeños productores de quinua y de kiwicha, productos que vienen incursionando en los mercados internacionales, enfrentan una situación de "monopsodio" donde muchos productores dispersos enfrentan pocos compradores (acopiadores), quienes están en capacidad de controlar el mercado, favorecidos por la creciente liberalización del comercio.

Los otros productos alimenticios que las mujeres campesinas destinan a la venta, como papa, maíz, trigo, cebada, tarwi, arvejas y hortalizas, así como flores, los comercializan en mercados y ferias regionales, incluidos los mercados de las capitales y en el caso de las campesinas de Quispicanchis, también lo hacen en la región vecina de Puno. La comercialización de animales menores de su crianza, vivos o beneficiados, la hacen en forma similar a la de los productos vegetales, excepto la venta de cuyes, que algunas campesinas de Quispicanchis, también los comercializan procesados en la ciudad de Cusco, atendiendo la demanda de restaurantes y hoteles.

El destino de la producción agrícola en las dos provincias tiene un comportamiento diferenciado según las especies cultivadas. Se distingue claramente, el carácter comercial que han adquirido la quinua y la kiwicha, particularmente en la provincia de La Unión, donde el $100 \%$ de la kiwicha y un 95\% de la quinua producidas son vendidas a través de sus propias asociaciones de comercialización a los acopiadores que acuden hasta los predios agrícolas y en menor medida, organizando sus propias exportaciones. En Quispicanchis venden sólo un pequeño margen de su producción de quinua, no se ha registrado producción significativa ni venta de kiwicha.

La producción de papas y de maíz, que son importantes en ambas provincias, es destinada preferentemente al autoconsumo familiar, en una proporción aproximada de $80 \%$ en el caso de las papas en ambas provincias, 93\% del maíz producido en La Unión y 55\% en Quispicanchi. Los saldos son comercializados generalmente en los mercados regionales. Cobra relativa importancia comercial la producción de hortalizas y flores; cerca del $60 \%$ de las hortalizas producidas en ambas provincias son para venta, igual destino tiene la totalidad de flores cultivadas en Quispicanchis. Entre los diversos cultivos que mantienen importancia en ambas provincias se cuentan igualmente las habas, arvejas y el tarwi, cuyo destino es mixto, en proporciones aproximadas de $40 \%$ para venta y $60 \%$ para autoconsumo, excepto la arveja en La Unión que es sólo para autoconsumo. La alfalfa producida en las citadas provincias es destinada a la crianza de ganado de los mismos agricultores.

La generalidad de mujeres agricultoras entrevistadas han referido que al haberse producido en el mercado una mayor demanda y valoración de sus productos tradicionales andinos, adoptaron diversos cambios y mejoras en sus cultivos, como también en la preparación, transformación y comercialización de sus productos, a fin de lograr una mejor cotización de sus ofertas. En La Unión $27.8 \%$ de productoras aumentaron la producción de kiwicha y $16.7 \%$ aumentaron la quinua, $11.1 \%$ aumentaron kiwicha y maíz, asociados, conjuntamente, sectores similares de campesinas incrementaron su producción de kiwicha y papa, de kiwicha y hortalizas, de kiwicha y quinua y de maíz con hortalizas, todos asociados En Quispicanchis 33.3\% de productoras incrementaron la producción de hortalizas, $16.7 \%$ incrementaron el cultivo de flores y otro $16.7 \%$ de quinua conjuntamente con hortalizas. Así mismo, todas las campesinas entrevistadas en La Unión refirieron que mejoraron la calidad de sus cultivos, 65\% de las entrevistadas en Quispicanchis también mejoraron sus cultivos. Sectores minoritarios de campesinas 
entrevistadas de ambas provincias refieren que, con la misma finalidad, han recibido capacitación en fertilización, limpieza y deshierbo de sus cultivos.

Las mujeres entrevistadas preparan sus productos, previo a su venta, de acuerdo a las características particulares de cada especie y las condiciones obtenidas en la cosecha, con el fin de lograr un mayor beneficio en su mercadeo. Las operaciones que realizan para dicho fin son manuales y utilizan equipos, herramientas y utensilios elementales. Así, la quinua obtenida en las dos provincias es seleccionada, sometida a limpieza, para quitarle la paja y piedras y es desamargada por lavado y secado, la kiwicha es sometida a un tratamiento similar, sin el desamargado, el maíz es deshojado, secado al sol, desgranado y seleccionado. Las hortalizas son seleccionadas, lavadas y acondicionadas y, similarmente, las flores son seleccionadas y acondicionadas.

La kiwicha producida en La Unión es vendida principalmente a rescatistas que acuden hasta los predios agrícolas. Los otros productos agrícolas, en ambas provincias son comercializados por las pequeñas agricultoras en los mercados y ferias locales y, en el caso de Quispicanchis, lo hacen también en la ciudad de Cusco y en la vecina región de Puno

Todas las mujeres entrevistadas de Quispicanchis y más del 75\% de las de la Unión venden también los animales vivos de su crianza o bien sus carnes, huevos, leche o subproductos, como queso, charqui o platos de comida. Las de La Unión refieren que los animales vivos, tales como vacunos, equinos, gallinas y cuyes los venden en el mercado local (Cotahuasi). Las mujeres de Quispicanchis diversifican sus mercados, los vacunos los venden en el Cusco, 67\% de ellas venden las gallinas y otras aves en el mercado local (Urcos) y $33 \%$ en restaurantes de Cusco, los cuyes los venden 70\% de las mismas en el mercado local y $30 \%$ de ellas en restaurantes de Cusco.

Una mayoría relativa de $58 \%$ de entrevistadas de La Unión afirma no haber mejorado sus ingresos económicos por la venta de sus productos en los últimos ańos, mientras que $79 \%$ de mujeres de Quispicanchis considera que sí han mejorado sus ingresos en dicho lapso. Las entrevistadas de La Unión que afirman haber mejorado sus ingresos (42\%), explican que dicha mejora fue por la mayor cantidad de quinua vendida y con mejor precio. La notable mayoría de entrevistadas de Quispicanchis, que han mejorado sus ingresos, lo explica porque aumentaron sus ventas de hortalizas y flores, principalmente, $y$, en menor medida por sus mayores ventas de quinua.

En la medida que los productos de los pequeños productores alimentarios se hacen más comerciales y más aún, cuando ingresan a los mercados de exportación, los sistemas de comercialización se diversifican, generalmente por concentración en el acondicionamiento, transformación y distribución o exportación, controlados por cadenas de rescatistas, acopiadores, comerciantes mayoristas y eventualmente empresas industriales. Los casos de la cochinilla, el ají, el sacha inchi y más recientemente de la quinua y la kiwicha son ilustrativos de dicho comportamiento.

Una estrategia competitiva destinada a incrementar la productividad en los minifundios de la sierra es el desarrollo de cadenas productivas de productos con potencial exportable, que incluya la transformación agroindustrial en áreas agrícolas. La innovación en el campo del desarrollo rural tiene importancia particular en lo relativo a la adopción de formas empresariales, en la medida en que éstos impliquen soluciones técnicas y gerenciales acordes al contexto socio económico. No podrá dejarse de lado la necesidad de dotar de un respaldo cercano de investigación y desarrollo tecnológico para apoyar y orientar las actividades agropecuarias y de transformación agroindustrial que se emprendan.

Las mujeres campesinas demuestran una elevada sensibilidad ante las posibilidades que ofrecen los cambios tecnológicos, en la medida que éstos se den bajo la óptica de la seguridad productiva en la unidad familiar, con mínima inversión de recursos materiales y compatibles con sus formas de manejo y capacidades productivas. El desempeño de la mujer, adicionalmente a la actividad productiva agropecuaria, incluye crecientemente la transformación, procesamiento y comercialización de productos agroalimentarios. Las campesinas del sur andino asumen para sí las responsabilidades tanto de los trabajos domésticos como de las actividades productivas agrícolas y no agrícolas, incluidas las diversas estrategias productivas y de sobrevivencia de sus unidades familiares. Las mujeres campesinas pueden ser más sensibles a los efectos positivos del cambio tecnológico y a las posibilidades de aplicación de consejos técnicos ${ }^{11}$.

Las experiencias de procesamiento y venta de alimentos, que han emprendido sectores de las campesinas entrevistadas, demuestran que es posible abrir

11 Solís A. Clara. Aporte de las Mujeres Rurales al Desarrollo. IICA 1990. 
espacios propicios para el potenciamiento del rol económico de la mujer, siempre que encuentren alternativas viables de comercialización, crédito, adecuación tecnológica y organizativa. Al respecto es destacable la necesidad de diversificar las actividades que ayuden a la creación de empleo femenino en el mundo rural, fomentando la formación técnica y organizacional, con acceso a nuevas tecnologías, que den valor agregado a los productos ofertados por los pequeńos agricultores.

\section{Potencialidades y limitantes tecnológico culturales en la actividad productiva de la mujer campesina}

La división técnica sexual del trabajo predetermina en la mujer un obstáculo estructural para el acceso a nuevas tecnologías, sin embargo, el análisis de los datos encontrados nos revela que son diversos los factores que definen su participación en la producción, tal como lo demuestran, por ejemplo, los vínculos que establece con el mercado, que estimulan la participación productiva y diversifican la actividad de la mujer, mientras que las restricciones impuestas a la mujer, que se manifiestan principalmente por los escasos niveles de educación y capacitación técnica que alcanza, así como la titularidad sexista del predio agrícola, son depresoras de las capacidades de desarrollo de la mujer campesina.

El nivel de educación alcanzado por las mujeres entrevistadas en las dos provincias nos revela, en general, que las campesinas de La Unión tienen un mayor nivel educativo, $74 \%$ de ellas tienen secundaria y un pequeño sector de $5 \%$ de las mismas tienen educación superior, $21 \%$ de las mismas tenían sólo nivel primario de educación. Las mujeres de Quispicanchis denotan escasos niveles educativos, cerca del 10\% de estas son analfabetas y un gran sector de $48 \%$ solo tiene nivel primario, con un margen menor, de $43 \%$, que alcanzan educación secundaria. El nivel educativo de los cónyuges varones supera al de las mujeres en las dos provincias. En La Unión, se registra un importante sector de $22 \%$ de varones con educación superior, 57\% con secundaria y $22 \%$ primaria. En Quispicanchis, $10 \%$ de los varones son analfabetos, similarmente a las mujeres, pero un margen algo mayor de estos tienen educación secundaria, $50 \%$.

Entre las acciones referidas por las campesinas entrevistadas para aprovechar las mejoras del mercado respecto a la valoración asignada a los productos andinos, como la quinua, kiwicha, papa, maíz y tarwi se aprecia una diversidad de opciones asumidas. En La Unión, dos grupos, cada uno de $44 \%$ de mujeres, aprovecharon las oportunidades de capacitación ofrecidas para mejorar sus cultivos, por otro lado, otro grupo similar mejoró el abonamiento de tales cultivos, un tercer grupo de $12 \%$ de mujeres buscó asesorarse de otras agricultoras. En Quispicanchis, un grupo mayoritario de 67\% de mujeres mejoró la limpieza y deshierbo de sus cultivos y cuatro grupos menores, cada de uno de $8 \%$ de mujeres, optó: a), aprovechar las oportunidades de capacitarse, b) mejorar el abonamiento de sus cultivos, c) contrataron con restaurantes y ferias la venta de sus productos y d) implementaron fitotoldos para dichos cultivos. Una gran mayoría de mujeres de La Unión refirieron haber afrontado dificultades económicas para hacer las mejoras en sus cultivos; sólo una minoría de las entrevistadas de Quispicanchis tuvo similar respuesta. Las causas de tales dificultades fueron atribuidas principalmente a la falta de asistencia técnica y los mayores gastos que les ha demandado hacer los cambios.

En cuanto a la forma cómo aprendieron a combatir las plagas y enfermedades de las plantas, 50\% de mujeres de La Unión y 89\% de Quispicanchis refirieron que lo hicieron por su relación con otros agricultores y, por otro lado, 50\% de mujeres de La Unión y 11\% de Quispicanchis, refirieron haber recibido capacitación de alguna institución.

Una mayoría de $74 \%$ de mujeres entrevistadas de La Unión y 37\% de Quispicanchis refirieron haber recibido asistencia técnica, entrenamiento o alguna capacitación en los últimos años sobre técnicas de cultivo El 100.0\% de las mujeres entrevistadas de la provincia de La Unión mencionan que la asociación especializada en desarrollo sostenible (AEDES) y el $100.0 \%$ de mujeres de la provincia de Quispicanchis mencionan que la Municipalidad distrital les ofreció la capacitación referida. En La Unión, el 71.4\% recibió asistencia en prácticas de cultivo y el $21.4 \%$ asesoría técnica, en cambio, en Quispicanchis el 25.0\% recibió asistencia en crianza de animales y dos grupos, cada uno de $17 \%$ de entrevistadas, recibieron asistencia en abonamiento y lucha contra enfermedades.

Sólo sectores relativamente minoritarios de las pequeñas productoras de alimentos de estas provincias se hallan incorporadas en organizaciones asociativas de productores o comercializadores de alimentos; $29 \%$ de entrevistadas de La Unión y 43\% de Quispicanchis refirieron estar asociadas. El total de asociadas de $\mathrm{La}$ 
Unión pertenece a la Asociación de Productores Orgánicos, la misma que se dedica al acopio y comercialización de kiwicha. De las asociadas de Quispicanchis, el $25 \%$ pertenece a la Asociación de Productores de Maiz, $62 \%$ pertenece a otras dos asociaciones de productores agrícolas, y $13 \%$ a la Asociación de Ganaderos.

Mayorías de 84\% de campesinas de La Unión y $76 \%$ de Quispicanchis manifestaron sus expectativas de introducir próximamente algunas mejoras en sus cultivos. En la Unión pretenden mayormente mejorar la calidad de sus productos, así como las variedades de cultivos, selección de semillas y mejorar el almacenamiento de sus productos. En Quispicanchis buscarán mejoras en sus cultivos de hortalizas, aumentar sus cultivos de quinua, principalmente, y de kiwicha y, en menor medida, mejorar la fertilización de sus cultivos. Son algo menores los sectores de estas pequeñas productoras de alimentos que manifiestan interés por introducir mejoras en la conservación, almacenamiento y procesamiento de sus productos. En todos los casos, son mayorías notorias en ambas provincias que esperan obtener mayores ganancias económicas de las mejoras que piensan introducir en sus cultivos, como también en la conservación y procesamiento de sus productos.

Una gran mayoría de $94 \%$ de entrevistadas de La Unión consideran que necesitarán capacitación y entrenamiento para poder lograr las mejoras propuestas de sus cultivos, como también en la conservación y procesamiento de sus productos, mientras que sólo $42 \%$ de la entrevistadas de Quispicanchis manifiestan dicha necesidad. La diferente respuesta percibida en este punto, posiblemente se debe a la mayor oferta en capacitación que se ofrece en la provincia de La Unión, donde el MINAGRI y una ONG local desarrollan regularmente campańas en este campo, mientras que en Quispicanchis son escasas la oportunidades en que los campesinos pueden acceder a la capacitación.

Prácticamente todas las entrevistadas en ambas provincias manifiestan que necesitarían un préstamo o ayuda económica para facilitar las mejoras que requieren hacer en sus cultivos y, en el caso de la Unión, también lo necesitarían para mejorar la conservación y procesamiento de sus productos. En La Unión hacen referencia que pueden solicitar préstamos a AGROBANCO, tanto para mejorar sus cultivos como para procesar sus productos. En Quispicanchis no se registra información alguna al respecto.

En la provincia de La Unión sólo un 7\% de las entrevistadas estarían dispuestas a asociarse con otros productores para mejorar sus cultivos, en cambio un $40 \%$ de las mismas sí lo haría con el fin de mejorar la conservación y procesamiento de sus productos. En Quispicanchis el $50.0 \%$ de entrevistadas refieren que estarían dispuestas a asociarse para mejorar sus cultivos. No hay información de esta provincia respecto al procesamiento de productos.

Las entrevistadas de La Unión que prefieren no asociarse con otros productores tanto para mejorar sus cultivos como para mejorar la conservación y procesamiento de productos, se justifican señalando que prefieren hacerlo individualmente y también porque no tienen confianza en trabajar con socios.

En relación a las mayores dificultades que las entrevistadas refieren afrontar para mejorar la calidad y presentación de sus productos, encontramos que en La Unión 50\% de dichas mujeres manifiestan que les falta dinero para invertir, un segundo grupo de $21 \%$ de mujeres afirman que los precios de sus productos en el mercado son muy bajos, otros dos grupos, cada uno de $14 \%$ de entrevistadas refieren que les falta asesoría técnica y las otras citan que las vías de comunicación y de transporte, son deficientes. Entre las entrevistadas de Quispicanchis, 38\% refieren que sus predios son muy pequeños y producen poco, $31 \%$ de las mismas citan que necesitan riego por aspersión y otro grupo de $25 \%$ manifiestan que les falta tiempo por las múltiples ocupaciones a las que se dedican.

La producción agropecuaria en las pequeńas unidades agrarias, productoras de alimentos de la sierra, se desenvuelve en condiciones críticas, en razón a las limitaciones económicas, culturales y tecnológicas que dicho sector afronta. La tecnología preponderantemente tradicional que utilizan es una respuesta adaptativa a su situación, los bajos rendimientos logrados sólo les permite márgenes de sobrevivencia, incluso diversificando sus ingresos, tanto en actividades agrícolas como en no agrícolas, incluyendo en este último campo el procesamiento de sus productos, que las mujeres campesinas vienen realizando en forma creciente en los últimos ańos. No existen canales de comercialización ni políticas de precios que sean favorables a la economía campesina. Los escasos e inconexos programas de capacitación y extensión técnica, generalmente no benefician a las mujeres agricultoras.

No obstante el papel productivo central de la mujer campesina su trabajo es "invisibilizado", tiene un limitado acceso y control sobre recursos y servicios, tales como la titularidad de la tierra, crédito y servi- 
cios de extensión y capacitación, lo que constituye una barrera, que impide su desenvolvimiento y desarrollo personal y productivo. Es determinante la restricción y discriminación de las mujeres campesinas al acceso a la tierra que, a su vez, limita su acceso a los servicios y otros recursos, tales como apoyos financieros, nuevas tecnologías y una participación efectiva en organizaciones rurales y eventos del sector agrícola, debilitando seriamente la efectividad y eficiencia de su desempeño. La capacitación y asistencia técnica se orienta excluyentemente hacia los hombres.

La mujer productora de alimentos vinculada fundamentalmente a las economías campesinas tiene una doble barrera para acceder a la oferta tecnológica: su condición de mujer y su condición de pobreza. Sobre las restricciones en la oferta de servicios y recursos crediticios para las mujeres, los datos nos indican que existen limitaciones en la demanda por parte de las propias mujeres, debido tanto a la ausencia de respaldo formal (titulo de propiedad del predio) para amparar su solicitud de crédito, como a la falta de conciencia de sus derechos como productora agrícola, a lo cual se agrega que todavía no se ha difundido las modalidades de carácter asociativo y empresariales para canalizar el apoyo externo, bien sea del estado o de instituciones privadas.

Las relaciones de género predeterminadas por la matriz cultural han dado lugar a una especialización genérica en el dominio tecnológico por parte del hombre y la mujer del campo, atendiendo fundamentalmente a la asignación de roles que cumplen los miembros de la familia campesina. Una tendencia hacia la especialización por género comienza según se trate de sistemas productivos agropecuarios de tipo intensivo, los cuales emplean maquinaria agrícola como tractores, arados por tracción animal, fumigadoras y otros equipos y herramientas mecanizadas, generalmente manejados por los varones, quienes son los convocados a la capacitación y transferencia de tecnologías, mientras que en los sistemas productivos extensivos, más frecuentes en las pequeńas unidades agrarias, generalmente predomina la participación femenina y se caracteriza por el manejo productivo tradicional, con herramientas manuales, recursos e insumos generados dentro de la pequeña unidad agraria, como el uso de semillas y guano de corral, que valora más el acervo cultural y productivo tradicional.

El trabajo de campo realizado en cuanto a la aplicación de tecnologías por las mujeres en las unidades campesinas, nos ha permitido delinear algunas anotaciones centrales en lo relativo al sentido cómo la mujer está integrada en los diversos procesos productivos y comerciales. Es remarcable, dentro de ello, replantear el alcance del concepto de división sexual del trabajo. En el sistema productivo campesino encontramos multiplicidad de labores productivas compartidos entre hombres y mujeres, según la matriz ideológica y cultural sobre la cual se construye la "división del trabajo" y las relaciones de poder que condicionan el acceso y el control sobre los recursos. El cómo se conjugan estos factores en la realidad da cuenta de la gran diversidad de roles y situaciones que cumple la mujer campesina y su relación con la predeterminación biológica y sexual. Dado el caso, por ejemplo, de las mujeres jefas de hogar, que en ausencia del cónyuge, quedan con la responsabilidad de la unidad productiva, asumen tareas y adoptan decisiones que eran competencia del hombre. Es decir la diferencia sexual por sí misma no es inflexible en los roles de las mujeres campesinas.

Si la contribución de las mujeres es decisiva en la producción y reproducción de las pequeñas unidades agropecuarias, también lo es en las decisiones relativas a la gestión de las unidades. La relativa flexibilidad en la división del trabajo y en la toma de decisiones entre hombres y mujeres, está ausente en el acceso a los recursos productivos, es decir existe una amplia brecha genérica entre lo que la mujer aporta y lo que recibe a cambio.

Los programas dedicados a la adopción de tecnologías por parte de las mujeres campesinas deben considerar, adicionalmente a ofrecer insumos y programas de difusión de innovaciones tecnológicas, la interacción con los factores socioeconómicos, entre los cuales son más gravitantes la escasa dotación de tierras y pobreza de las mismas, la falta de acceso a recursos productivos como crédito, los altos precios de los insumos, el acceso al mercado y deficiencias en la infraestructura existente.

Los obstáculos que enfrenta la unidad productiva campesina en cuanto a la disponibilidad y adecuación de la oferta tecnológica, se debe sin duda a que esta oferta no corresponde a las necesidades y a la demanda de innovación tecnológica prioritaria para productores campesinos. En otros términos, se puede decir que la investigación y generación tecnológica no posee mecanismos participativos para levantar los requerimientos de asistencia técnica de la población a la que supuestamente presta sus servicios. La baja receptividad o 
aceptación de la oferta tecnológica en la producción campesina tiene que ver con el diseño y desarrollo de los paquetes tecnológicos en condiciones de estación experimental, y por lo tanto fracasan cuando se los aplica a los sistemas campesinos frecuentemente limitados en recursos y con altos índices de riesgo productivo y económico ${ }^{12}$.

Uno de los factores de esta inviabilidad ha sido también el desconocer el protagonismo de la mujer campesina en el proceso productivo y en la toma de decisiones, muchas veces compartidas con el varón para la innovación tecnológica y, en general, en los ámbitos y prácticas específicas de su control, que se da, por ejemplo, en que sólo un $17 \%$ de mujeres reciben capacitación en selección de semillas, frente a un $70 \%$ de varones. El hecho de que la transferencia tecnológica haya carecido de un enfoque participativo y de género, ha determinado su orientación unilateral hacia los varones, contribuyendo a crear una brecha $y$ un desequilibrio en el conocimiento tecnológico entre hombres y mujeres del campo, contribuyendo en el escaso desarrollo general de los niveles tecnológicos y productivos de la pequeña agricultura de la sierra.

Otros aspectos que han trabado el proceso de transferencia tecnológica son: el carácter aislado de la promoción de nuevas tecnologías, la falta de elementos que lo sustenten, como crédito, organización, planificación y seguimiento técnico, la ausencia de una perspectiva de género, que ha impedido cumplir por quienes proporcionan la "tecnología mejorada" un trabajo efectivo con los actores, mayormente mujeres, el desconocimiento de sus potencialidades y conocimientos, los canales de información tradicionales, desestimando los saberes enriquecidos por sus tradiciones y ańos de experiencia productiva, que ha sustentado a una población campesina, en condiciones sociales y ecológicas sumamente adversas.

El mayor acceso al sistema educativo y su mayor permanencia son los principales cambios necesarios para la educación de las mujeres rurales, en razón a que la educación es un medio fundamental para alcanzar el desarrollo humano, superar la pobreza y lograr la seguridad alimentaria. No obstante los avances logrados al presente, se observa a nivel nacional, que la población femenina adulta y rural sigue siendo el sector que presenta los más bajos niveles de educación. La

12 Riveros, H, Lucio-Paredes, A. y Blanco, M. Una Mirada a experiencias exitosas de agroindustria rural en américa latina. IICA. San José Costa Rica. 2009. relación entre educación y desarrollo rural tiene que ver con la teoría de que una mayor educación facilitará la adopción de nuevas tecnologías, adecuadas a las condiciones naturales y socio económicas, con mayor productividad para transformar las condiciones de vida en el campo ${ }^{13}$.

\section{Conclusiones y recomendaciones}

La información disponible en el Perú acerca de los vínculos entre mujer y tecnología es escasa, similarmente a lo referente a tecnología y las diversas formas de su adopción o adaptación en el manejo productivo agropecuario y de transformación de productos agroalimentarios en las pequeñas unidades agrícolas de la sierra, del nivel y alcances de sus logros y tampoco de las limitaciones de diverso género que atentan contra la productividad del trabajo y la economía de la unidad familiar. La visión unilateral generalizada de los programas orientados a la educación y promoción tecnológica en el ámbito agrario rural no comprende los motivos ni el sentido del rol social de la mujer, soslayando las potencialidades de desarrollo sostenido y equitativo de las regiones andinas, que sería posible alcanzar optimizando la participación productiva de la mujer.

La división del trabajo por género predetermina en la mujer un obstáculo estructural para el acceso a nuevas tecnologías, sin embargo, los resultados del estudio nos revela que son múltiples los factores que definen la participación tecnológica de la mujer campesina, como por ejemplo, los vínculos que establece con el mercado, que diversifican su actividad, tanto en producción agropecuaria como también estimulando el procesamiento de sus productos y la diversificación de su mercado, mientras que las restricciones impuestas a la mujer en educación y capacitación técnica y la titularidad sexista del predio agrícola, actúan como depresoras de sus capacidades de desarrollo.

Las potencialidades tecnológico productivas de la mujer campesina del sur andino se hallan condicionadas principalmente por su capacidad económica, expresada en la disponibilidad de tierras irrigadas. Encontramos que se adoptaron innovaciones productivas más significativas en las unidades familiares de la provincia de La Unión, en predios mayores de $2 \mathrm{Ha}$. de

13 Cotlear, Daniel. Desarrollo Campesino en Los Andes: Cambio Tecnológico y Transformación de las Comunidades de la Sierra del Perú. IEP Lima 1989. 
extensión, conducidos generalmente por mujeres, habiendo incrementado su producción y productividad agrícola de quinua y kiwicha, a la vez que, con la guía de una entidad promotora, han conformado asociaciones de productores para la comercialización de dichos productos en el país y en el exterior.

En la provincia de Quispicanchis, donde las unidades familiares agrícolas son más pequeñas y con escaso o nulo apoyo tecnológico-económico institucional, destaca la intensificación del trabajo y capacidad creativa de la mujer, en su búsqueda de oportunidades de mercado para colocar sus diversos productos de microescala comercial, cuya conformación la adaptan en especies, variedades y presentación a la demanda de los consumidores. Excepcionalmente, se encontró en esta provincia la presencia de pocas asociaciones de mujeres criadoras de cuyes, conformadas con apoyo tecnológico, para la crianza y comercialización de dicha especie.

El procesamiento industrial de productos agrarios se viene introduciendo en la provincia de La Unión, donde se han establecido pequeños molinos de propiedad familiar, conducidas mayormente por mujeres agricultoras, para prestar servicios de molienda, laminación y otras operaciones que dan valor agregado a los granos andinos y otros cereales producidos en la zona. En Quispicanchis, las mujeres elaboran productos de consumo final, consistentes en platos de comida a base de cuyes, que venden directamente a consumidores en ferias locales y también los comercializan en restaurantes y hoteles de la ciudad de Cusco.

En relación a la adopción de tecnologías, el estudio confirma que las mujeres campesinas productoras de alimentos cuentan con criterios de peso que les orienta la generación, validación y adopción de alternativas tecnológicas, tal como se evidencia en la utilización de insumos y el manejo de la parcela, como es el caso de la introducción de nuevas variedades de kiwicha en la provincia de La Unión y el incremento de la producción de hortalizas y flores, así como las mejoras en la crianza de cuyes en la provincia de Quispicanchis. Entre los criterios en los cuales se basan ellas en la selección de tecnologías figuran el impacto de los costos sobre el ingreso y economía familiar y sus posibilidades de comercialización.

Las prácticas tecnológicas de las pequeñas unidades de producción de alimentos muestran una combinación de patrones tecnológicos tradicionales con limitada mecanización y de escasas prácticas perfeccionadas. Entre los aspectos que dificultan la transferencia tec- nológica a los pequeños productores agrarios se identifica el carácter aislado de la promoción de tecnologías innovadas y su desajuste conceptual a las condiciones socioeconómicas precarias de los campesinos y que a su escasa presencia en el campo no se acompaña respaldo alguno para su financiación ni de recursos complementarios, adicionalmente no se provee seguimiento técnico a las campañas realizadas. Dichas limitaciones son más visibles en el caso de la mujer.

La investigación realizada demuestra la gran riqueza tecnológica que maneja la mujer campesina, lo que no aparece contemplado ni en las políticas ni en los programas de investigación y extensión tecnológica oficiales e institucionales, que tienen una percepción de la realidad con una óptica desarrollista, sin tomar en cuenta el conocimiento y la racionalidad productiva campesina en esta materia.

Las actividades de procesamiento y comercialización de productos agroalimentarios constituyen espacios en los que las mujeres campesinas de las provincias de La Unión y Quispicanchis se posicionan en situación expectante, dada su participación productiva muy visible y su notable disposición para interactuar en el mercado, aún con las limitaciones económicas y socioculturales que afrontan.

Las escasas experiencias asociativas (casos de la crianza de cuyes en Quispicanchis y la producción y comercialización de kiwicha y quinua en La Unión) para la transformación y comercialización de alimentos, permiten señalar que dicha alternativa puede ser un ámbito propicio para el potenciamiento del rol económico de la mujer campesina, previsto que tenga el respaldo económico (crédito accesible), adecuación tecnológica y organizativa.

El alejamiento geográfico, la precariedad de las vías de transporte y la dificultad de acceso a la información; que afrontan por lo general las economías campesinas, demandan optimizar el uso de tecnologías de la información con el fin de abrir nuevos espacios de aprendizaje formales e informales, capaces de contribuir significativamente al desarrollo rural y mejorar la productividad del trabajo femenino. Es necesario facilitar la adopción de nuevas tecnologías y prácticas administrativas en la difusión de información y. conocimientos que contribuirían a elevar la productividad agrícola y facilitarían el desarrollo de sinergias entre los pequeños agricultores.

La mujer campesina de la región andina, principal productora de alimentos del país, que manifiesta una 
amplia apertura hacia la adopción de tecnologías innovadas, no obstante las serias limitaciones de recursos materiales y culturales que afronta, demanda una mayor atención en el ámbito de la investigación científica y tecnológica y de extensión, por parte del sector académico, para profundizar el conocimiento en los diversos campos que demanda la producción agropecuaria y de procesamiento productivo, toda vez que se trata de un medio con ecosistemas especiales, poco frecuentes en el mundo, los cuales albergan una gran diversidad de especies vegetales y animales y una riqueza cultural agropecuaria milenaria, como potencialidades que permitan encarar la necesidad de impulsar el desarrollo económico campesino.

\section{Referencias bibliográficas}

Berrío, A. Cárdenas, S. y Zuluaga, G. (2009). Cosecha de aprendizajes. Experiencias de mujeres para la soberanía alimentaria. Lima.

Самасно, G. (2010). Mujeres migrantes: Trayectoria laboral $y$ perspectiva de desarrollo humano. CLACSO. Quito, Ecuador.

Eguren, F. (2011). Seguridad alimentaria. SEPIA XIV. PiuraPerú.

Giraldo, O. (2010). Campesinas construyendo la utopia: Mujeres, organizaciones y agroindustrias rurales. Cuadernos de desarrollo rural. PUJ. Colombia.

IAASTD (2008). Informe científico. Resumen del informe publicado en 2008 por evaluación internacional de las ciencias y las tecnologías para el desarrollo. IAASTD.
Instituto Nacional de Investigación Agraria (2009). Segundo informe sobre el estado de los recursos fitogenéticos para la alimentación y la agricultura. Perú: INIA.

Kanashiro, L. (2014). ¿Quién alimentaría el mundo? Una oportunidad para la agricultura familiar del cacao peruano. Conexión ESAN.

KuAN, J. (2009). La crisis alimentaria: retos y oportunidades en los Andes. CONDESAN - FAO. No 9. Santiago de Chile.

Lizana, Carolina (2015). El rol de la mujer en la agricultura. Facultad de Ciencias Agrarias. Universidad Austral de Chile.

LOAYZA, S. (Julio 2015). La mujer campesina en la agricultura y seguridad alimentaria. Revista de Sociología. Facultad de Ciencias Sociales, UNMSM. Lima

Organización de las Naciones Unidas para la Agricultura y la Alimentación. (2009). El estado mundial de la agricultura y la alimentación. Roma.

Peru Opportunity Fun. (2011). Diagnóstico de la agricultura en el Perú. Infome Final. Lima.

Rello, F. y SaAvedra, F. (2013). Diversificación productiva y transformación estructural en México: Estudios de caso en tres regiones. Investigación Económica. Vol 72. Universidad Nacional Autónoma de México. México.

SAENGer, C. (2001). Equidad y género en la agricultura sostenible. Ed. Flora Tristán. Lima.

SAN Pedro, R. (1996). Género y ruralidad: las mujeres ante el reto de la desagrarización. Guarante. S.L. Madrid, España.

Seminario Internacional de la mujer rural (2011). Cambios desafios y persistencias en América Latina. Lima. 